\title{
Effect of parity on reproductive performance sows of different breeds
}

\author{
R. Klimas ${ }^{1}$, A. Klimiené ${ }^{1}$, W. Sobotka ${ }^{2}$, W. Kozera ${ }^{3}$ \& P. Matusevičius ${ }^{4 \#}$ \\ ${ }^{1}$ Klaipèda University, LT-92294 Klaipèda, Lithuania \\ ${ }^{2}$ Department of Animal Nutrition and Feed Science, University of Warmia and Mazury in Olsztyn, LT-10-719 Olsztyn, \\ Poland \\ ${ }^{3}$ Department of Pig Breeding, University of Warmia and Mazury in Olsztyn, PL-10-719 Olsztyn, Poland \\ ${ }^{4}$ Department of Animal Breeding and Nutrition, Lithuanian University of Health Sciences, Veterinary Academy, LT-47181 \\ Kaunas, Lithuania
}

(Received 7 February 2019; Accepted 6 March 2020; First published online 13 July 2020)

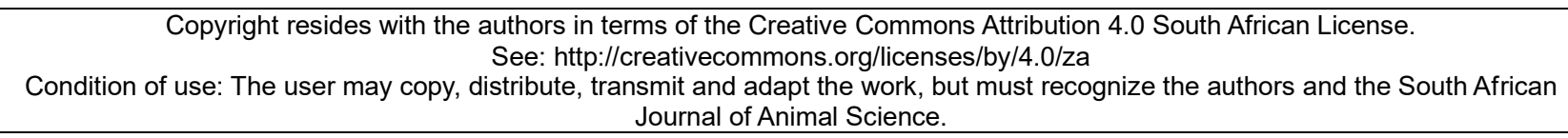

\begin{abstract}
The aim of this study was to determine the effect of parity on reproductive performance by sows of different breeds. The sows were raised on three farms, and had seven or more litters of not fewer than seven piglets. A total of 1511 litters from various parities of Lithuanian White $(\mathrm{N}=721)$, Large White $(\mathrm{N}=162)$ and Landrace $(N=628)$ sows were contained in the data that were used in this study. Multiparous sows had larger litters than primiparous sows. Piglet survival rate declined from parity 7. An increase in litter size was observed until parity 5 in Large White and until parity 6 in improved Lithuanian White $(P<0.05)$. In comparison with parity 1 , Landrace sows up to parity 5 showed not only increased prolificacy, but also increased number and litter weight of piglets at 21 days old, and the number and litter weight of weaned piglets $(P<0.01)$. The current findings indicate that sows of these breeds can be used effectively in breeding herds until parity 5 and parity 6 .
\end{abstract}

Keywords: Landrace, Large White, Lithuanian White, litter size

\#Corresponding author: paulius.matusevicius@Ismuni.lt

\section{Introduction}

The productivity of pigs is characterized by reproductive, growth, feed efficiency, carcass and meat quality traits. These reproductive performances are analysed most frequently: total number of piglets born (including stillborn), number and litter weight of piglets at 21 days old, number and weight of piglets at weaning, and survival rate of pre-weaning piglets. Heritability of these reproductive traits is generally low (Hanenberg et al., 2001; Bidanel, 2011; Nagyne Kiszlinger et al., 2013; Sevon-Aimonen \& Uimari, 2013). Reproductive phenotypes are influenced greatly by environmental factors, including feeding, housing and management conditions.

One of the most important breeding goals in the production of pig dam lines is to increase litter size (Dekkers et al., 2011; Franczak et al., 2017), which has a direct positive influence on the number of pigs produced (Bidanel, 2011). Reproductive indicators, particularly prolificacy, depend in large part on the breed of the sow (Knecht et al., 2015), body condition (Beyga \& Rekiel, 2010), and age or parity (Karpiesiuk et al., 2018). Poor reproductive performance is the most common reason (about 30\%) for sow culling (Zhao et. al., 2015). Maintaining sows in proper body condition requires adjustment of feed intake during gestation. However, sow parity has been found to exert varied effects on body condition. Maintaining body condition during lactation is important for producing high litter size at the next farrowing (Eissen et al., 2003; Thaker \& Bilkei, 2005). Takai and Koketsu (2008) demonstrated that litter size increased from the first to second parities, but not over subsequent ones. Arango et al. (2005) reported that litter size tended to increase from the first parity to the third. Knecht et al. (2015) observed that the highest reproductive performances of sows were in parities 3 and 4, whereas Hoving et al. (2011) found the highest reproductive performances in parities 3 to 5 . According to other authors, litter size increases from parity 1 through parities 5 (Čechova \& 
Tvrdon, 2006) and 6 (Škorjanc et al., 2007). Sows with smaller litter size in the first parity are at higher risk of being culled compared with more prolific sows (Guo et al., 2001).

In Lithuania, pig breeds are classified as maternal breeds (Lithuanian native, Lithuanian White, Large White and Yorkshire), an intermediate breed (Landrace) and paternal breeds (Duroc, Pietrain and their hybrids with Landrace pigs). The Lithuanian White breed is formed from old-type pigs (closed population) and improved-type pigs (open population). Since the end of 2002, Large White boars have been used to improve the open population of Lithuanian White pigs (Klimienè \& Klimas, 2011). Data collected in Lithuanian pig breeding centres (Klimas \& Klimiené, 2014) showed that $69.2 \%$ of sows of various breeds were culled before parity 4 . This had a negative impact on sow longevity for both the entire Lithuanian pig breeding population and individual breeding herds. The duration of reproductive use and optimal sow productivity depend directly on sow longevity (Serenius \& Stalder, 2004). A shorter productive lifetime of intensively managed sows has become a worldwide problem in pig farming.

The aim of this study was to analyse the effect of parity on the reproductive performance of sows of different breeds, which is the first comprehensive study of the type to be conducted in Lithuania.

\section{Materials and Methods}

By the end of 2012 , about $10 \%$ of all pigs at 14 Lithuanian pig breeding centres were improved Lithuanian White, 18\% were purebred Large White, and 20\% were purebred Landrace. The reproductive performance of the sows of these breeds was evaluated. They were raised on three large breeding farms (an average of 800 sows per farm) and had one to seven and more parities, which met Lithuanian pig breeding requirements. The traits assessed were total number of piglets born (born alive and stillborn); number, litter weight and individual weight of piglets at 21 days old; age, number, litter weight and individual weight of piglets at weaning; number of dead piglets in pre-weaning period and piglet survival rate. On the basis of the sow farrowing and offspring records of these farms, data that were recorded from 1 January to 31 December 2012 were used in this study. A total of 721 litters from Lithuanian White, 162 litters from purebred Large White, and 628 litters from purebred Landrace were included in the dataset. Reproductive performance data were analysed only from the sows whose number of piglets born alive was greater than six. According to Lithuanian pig breeding requirements, when a sow has fewer than seven piglets born alive, the parity is considered an 'emergency' and the data are excluded from the estimation of average prolificacy. Culling of sows was categorized into four groups: reproductive (do not rut, do not conceive, abort, low fertility/prolificacy (i.e., two emergency parities), insufficient milk yield, morbidity (diseases, leg weakness, injury), age and other aspects (poor progeny performance for fattening and carcass traits, unsatisfactory behaviour with piglets/aggression).

On the farm that produced purebred Large White piglets, weaning occurred at approximately 22 days old. On the farm that produced purebred Landrace piglets, weaning occurred at approximately 30 days old. Finally, on the farm that produced improved Lithuanian White piglets, weaning took place at approximately 32 days old. Thus, the length of lactation differed by breed. The gilts and sows were bred routinely with artificial insemination. Microclimate parameters (temperature, relative air humidity) in pig housing premises and the number of animals per stall complied with Lithuanian pig farming standards. At the three farms, the temperature ranged from $16^{\circ} \mathrm{C}$ to 20 in the farrowing room, from $18^{\circ} \mathrm{C}$ to $22{ }^{\circ} \mathrm{C}$ in premises for breeding, and from $22{ }^{\circ} \mathrm{C}$ to $26{ }^{\circ} \mathrm{C}$ in the nursery room. Relative humidity was approximately $70 \%$. Eight to twelve pregnant sows and 15 to 25 breeding gilts were housed in pens with stalls. The sows were moved to individual farrowing pens no earlier than five days prior to farrowing. The pigs were fed twice a day with a complete feed that was made on the farm. For the breeding gilts, one kilogram of feed contained $12.1-12.9$ MJ metabolizable energy, $16.5-16.6 \%$ protein and $3.2-3.7 \%$ fat. For the pregnant sows, one $\mathrm{kg}$ of feed contained $12.0-12.7 \mathrm{MJ}$ metabolizable energy, $13.5-16.6 \%$ protein and $2.0-2.2 \%$ fat. For the lactating sows, one $\mathrm{kg}$ of feed contained $12.2-12.8 \mathrm{MJ}$ metabolizable energy, $16.6-17.8 \%$ protein and $3.3-4.0 \%$ fat. Suckling piglets were provided with a supplement that contained $12.7-13.3 \mathrm{MJ}$ metabolizable energy, $18.0-22.7 \%$ protein and $4.4-7.3 \%$ fat. Finally, at weaning the piglets were fed a diet that contained 12.5 13.1 MJ metabolizable energy, $18.1-20.4 \%$ protein, and $4.1-6.6 \%$ fat.

The data were analysed by one-way analysis of variance using Statistica for Windows (version 8.0, StatSoft Inc., Tulsa, USA) following the basic guide to the statistical analysis of biological data by Tucker (2003). Results are presented as arithmetic means and the associated standard errors. The significance of differences between means was determined by Student's t-test. Differences in performance between primiparous (parity 1) and multiparous (parities 2 - 7 and later) sows were considered statistically significant at $P<0.05$. Sows of the three breeds were kept in different farms. Therefore, the effect of breed was confounded with farm and not estimated. 


\section{Results}

Across all breeds, sows that were culled farrowed an average of 3.7 times and were 28.1 months old. By parity, $20.0 \%$ of the sows were culled in parity $1,18.7 \%$ in parity $2,17.7 \%$ in parity $3,13.4 \%$ in parity 4 , $9.4 \%$ in parity $5,8.8 \%$ in parity 6 , and $12.0 \%$ in parity 7 or thereafter. Thus, $69.2 \%$ of all sows were culled before parity 4.

Parities 1 and 2 accounted for $23.4 \%$ of the recorded litters. Sows in parity 1 had the smallest total number of piglets born (11.4), which increased after first parity and reached 12.1 at the fourth parity, after which the total number born decreased slightly. Numbers born live and stillborn were greatest at the fourth parity and were significantly larger than those from the first parity. The number of stillborn piglets per litter increased with prolificacy. The average litter weight produced by Lithuanian White sows was $61.1 \mathrm{~kg}$ when the piglets were 21 days old and individual piglet weight at that time was $5.4 \mathrm{~kg}$. Litter weight and average piglet weight were not significantly affected by parity $(P>0.05)$. Relative to the first and second parities, weaning occurred at older ages as the sows produced more litters. The weight of piglets at weaning varied from $10.7 \mathrm{~kg}$ (parity 2) to $11.0 \mathrm{~kg}$ (parity 5). Pre-weaning mortality of the piglets was lowest in the first parity ( 0.2 piglets) and highest in the seventh parity and later $(0.5$ piglets, $P<0.01)$. Consequently, the survival rate of piglets in parity 7 and later was $2.5 \%$ lower $(P<0.01)$ compared with that in the first parity. From all litters, the survival rate of Lithuanian White piglets in the pre-weaning period was $97.3 \%$. The performance measures for Lithuanian White sows are presented in Table 1.

The majority of litters produced by Large White sows were in parities 2, 3, and $4(25.9 \%, 21.6 \%$ and $19.8 \%$ of the total, respectively) (Table 2). The average total number of piglets born to Large White sows over all parities was 13.5 , including 12.2 born alive and 1.3 stillborn. The total number born increased significantly until parity $5(P<0.001)$. After decreasing in parity 6 , the largest litters were produced in parity 7 and later, although the numbers of observations for parities 6 and $7+$ are small. The number of stillborn piglets per litter increased with prolificacy. For the litters born to Large White sows, the average age of piglets at weaning was approximately 22 days. Therefore, their characterization at 21 days was similar to their characterization at weaning. Third-parity sows produced more and heavier piglets than the primiparous sows $(P<0.05)$. The weights of individual piglets at 21 days old were similar across all parities. The numbers of dead piglets in the pre-weaning period in the litters produced by sows of all parities were numerically different, but differences were not statistically significant. The lowest piglet survival rate in the pre-weaning period was noted in the seventh parity and later (80.0\%).

The majority of litters of Landrace sows were produced by first parity sows (39.5\%). The average number of piglets born across all parities was 11.3 , including 11.0 born live and 0.3 stillborn. When compared with primiparous sows, multiparous sows in parities 3 and 5 delivered more live piglets $(P<0.01)$. The second, third and fifth parities had greater numbers of piglets and litter weights at 21 days old and at weaning compared with those from first parity sows $(P<0.05$ to $P<0.001)$. The weights of individual piglets at 21 days old and at weaning were similar across parities. The age of piglets at weaning ranged from 29.5 days for second parity sows to 30.9 days for sixth parity sows. Although piglets produced by second parity sows were weaned 1.1 days earlier $(P<0.01)$ than piglets of primiparous sows, they had the numerically highest weaning survival rate $(99.5 \%)$, but the difference was not statistically significant. The values that characterize the performance of Landrace sows across parities are presented in Table 3. 
Table 1 Means $( \pm$ SE) reproductive performance by parity of improved Lithuanian White sows

\begin{tabular}{|c|c|c|c|c|c|c|c|c|}
\hline & 1 & 2 & 3 & 4 & 5 & 6 & $>=7$ & Total \\
\hline No. of litters & 169 & 169 & 119 & 68 & 53 & 58 & 85 & 721 \\
\hline Total number of born & $11.4 \pm 0.07$ & $11.7 \pm 0.09^{*}$ & $11.7 \pm 0.11^{*}$ & $12.1 \pm 0.22^{\star \star \star}$ & $11.6 \pm 0.14$ & $11.8 \pm 0.17^{* *}$ & $11.5 \pm 0.12$ & $11.6 \pm 0.04$ \\
\hline Born alive & $11.2 \pm 0.05$ & $11.4 \pm 0.06$ & $11.4 \pm 0.07^{\star}$ & $11.5 \pm 0.11^{*}$ & $11.4 \pm 0.10$ & $11.5 \pm 0.10^{*}$ & $11.2 \pm 0.08$ & $11.3 \pm 0.03$ \\
\hline Stillborn & $0.2 \pm 0.05$ & $0.3 \pm 0.08$ & $0.3 \pm 0.09$ & $0.6 \pm 0.20^{\star *}$ & $0.2 \pm 0.09$ & $0.4 \pm 0.15$ & $0.2 \pm 0.10$ & $0.3 \pm 0.04$ \\
\hline \multicolumn{9}{|l|}{ At 21 days old } \\
\hline No. of piglets & $11.2 \pm 0.05$ & $11.3 \pm 0.06$ & $11.3 \pm 0.07$ & $11.4 \pm 0.11^{*}$ & $11.4 \pm 0.10$ & $11.3 \pm 0.10$ & $11.1 \pm 0.09$ & $11.3 \pm 0.03$ \\
\hline Litter weight (kg) & $60.8 \pm 0.27$ & $61.5 \pm 0.32$ & $61.8 \pm 0.38$ & $61.0 \pm 0.51$ & $61.4 \pm 0.57$ & $60.6 \pm 0.57$ & $60.3 \pm 0.48$ & $61.1 \pm 0.15$ \\
\hline Individual weight (kg) & $5.4 \pm 0.02$ & $5.5 \pm 0.03$ & $5.5 \pm 0.03$ & $5.4 \pm 0.05$ & $5.4 \pm 0.05$ & $5.4 \pm 0.05$ & $5.4 \pm 0.04$ & $5.4 \pm 0.01$ \\
\hline \multicolumn{9}{|l|}{ At weaning } \\
\hline Weaning age (days) & $31.4 \pm 0.19$ & $31.5 \pm 0.21$ & $32.0 \pm 0.22^{*}$ & $33.0 \pm 0.26^{\star \star \star}$ & $32.2 \pm 0.27^{\star}$ & $33.2 \pm 0.36^{* \star *}$ & $32.8 \pm 0.29$ & $32.0 \pm 0,10$ \\
\hline Wean number & $11.0 \pm 0.06$ & $11.1 \pm 0.07$ & $11.1 \pm 0.09$ & $11.1 \pm 0.15$ & $11.0 \pm 0.14$ & $11.2 \pm 0.11$ & $10.8 \pm 0.11^{*}$ & $11.0 \pm 0.03$ \\
\hline Litter weight (kg) & $121.2 \pm 0.55$ & $117.9 \pm 0.82^{*}$ & $121.9 \pm 0.93$ & $119.8 \pm 1.14$ & $121.0 \pm 1.19$ & $121.3 \pm 1.14$ & $117.7 \pm 1.18^{*}$ & $120.0 \pm 0.36$ \\
\hline Individual weight (kg) & $11.0 \pm 0.05$ & $10.7 \pm 0.07$ & $11.0 \pm 0.08$ & $10.8 \pm 0.10$ & $11.0 \pm 0.11$ & $10.9 \pm 0.10$ & $10.9 \pm 0.11$ & $10.9 \pm 0.03$ \\
\hline Dead number & $0.2 \pm 0.04$ & $0.3 \pm 0.05$ & $0.3 \pm 0.06$ & $0.3 \pm 0.10$ & $0.4 \pm 0.11^{*}$ & $0.3 \pm 0.08$ & $0.5 \pm 0.09^{\star \star}$ & $0.3 \pm 0.03$ \\
\hline Survival rate (\%) & $98.4 \pm 1.08$ & $97.4 \pm 1.16$ & $97.2 \pm 1.21$ & $97.0 \pm 1.30$ & $96.2 \pm 2.12^{*}$ & $97.3 \pm 1.26$ & $95.9 \pm 2.24^{\star \star}$ & $97.3 \pm 1.49$ \\
\hline
\end{tabular}

Significant effects compared with first parity: ${ }^{*} P<0.05,{ }^{* \star} P<0.01,{ }^{\star * \star} P<0.001$ 
Table 2 Means ( \pm SE) reproductive performance by parity of Large White sows in Lithuania

\begin{tabular}{|c|c|c|c|c|c|c|c|c|}
\hline & 1 & 2 & 3 & 4 & 5 & 6 & $>=7$ & Total \\
\hline No. of litters & 26 & 42 & 35 & 32 & 18 & 7 & 2 & 162 \\
\hline Total number of born & $11.6 \pm 0.48$ & $13.1 \pm 0.36^{*}$ & $13.7 \pm 0.44^{\star \star}$ & $14.4 \pm 0.60^{\star \star \star}$ & $15.3 \pm 0.61^{* \star *}$ & $13.1 \pm 0.86$ & $15.5 \pm 0.50$ & $13.5 \pm 0.22$ \\
\hline Born alive & $11.1 \pm 0.45$ & $12.3 \pm 0.35^{*}$ & $12.1 \pm 0.32$ & $12.6 \pm 0.46^{*}$ & $12.8 \pm 0.56^{*}$ & $12.0 \pm 0.58$ & $12.5 \pm 0.50$ & $12.2 \pm 0.18$ \\
\hline Stillborn & $0.5 \pm 0.15$ & $0.8 \pm 0.20$ & $1.6 \pm 0.31^{\star *}$ & $1.8 \pm 0.29^{\star *}$ & $2.5 \pm 0.29^{\star * *}$ & $1.1 \pm 0.55$ & $3.0 \pm 1.00$ & $1.3 \pm 0.12$ \\
\hline \multicolumn{9}{|l|}{ At 21 days old } \\
\hline No. of piglets & $9.9 \pm 0.30$ & $10.8 \pm 0.35$ & $11.2 \pm 0.40^{\star}$ & $10.6 \pm 0.39$ & $10.9 \pm 0.45$ & $10.9 \pm 0.46$ & $10.0 \pm 2.00$ & $10.7 \pm 0.16$ \\
\hline Litter weight (kg) & $72.1 \pm 2.27$ & $77.0 \pm 2.09$ & $80.2 \pm 2.67^{*}$ & $77.3 \pm 2.42$ & $79.2 \pm 3.03$ & $79.1 \pm 3.33$ & $72.5 \pm 14.50$ & $77.2 \pm 1.07$ \\
\hline Individual weight $(\mathrm{kg})$ & $7.3 \pm 0.23$ & $7.2 \pm 0.19$ & $7.2 \pm 0.24$ & $7.3 \pm 0.23$ & $7.2 \pm 0.28$ & $7.3 \pm 0.31$ & $7.3 \pm 1.45$ & $7.2 \pm 0.10$ \\
\hline \multicolumn{9}{|l|}{ At weaning } \\
\hline Weaning age (days) & $21.9 \pm 0.29$ & $22.0 \pm 0.28$ & $21.6 \pm 0.29$ & $22.0 \pm 0.39$ & $21.8 \pm 0.29$ & $21.4 \pm 0.20$ & $21.0 \pm 0.00$ & $21.9 \pm 0.13$ \\
\hline Wean number & $9.9 \pm 0.30$ & $10.8 \pm 0.35$ & $11.2 \pm 0.40^{*}$ & $10.6 \pm 0.39$ & $10.9 \pm 0.45$ & $10.9 \pm 0.46$ & $10.0 \pm 2.00$ & $10.7 \pm 0.16$ \\
\hline Litter weight (kg) & $72.4 \pm 2.21$ & $77.7 \pm 2.35$ & $80.5 \pm 2.76^{*}$ & $77.9 \pm 2.55$ & $80.2 \pm 3.09$ & $79.1 \pm 3.33$ & $72.5 \pm 14.50$ & $77.8 \pm 1.13$ \\
\hline Individual weight $(\mathrm{kg})$ & $7.3 \pm 0.22$ & $7.2 \pm 0.22$ & $7.2 \pm 0.25$ & $7.3 \pm 0.24$ & $7.3 \pm 0.28$ & $7.3 \pm 0.31$ & $7.3 \pm 1.45$ & $7.3 \pm 0.11$ \\
\hline Dead number & $1.2 \pm 0.35$ & $1.5 \pm 0.30$ & $1.0 \pm 0.29$ & $1.9 \pm 0.39$ & $1.8 \pm 0.49$ & $1.1 \pm 0.86$ & $2.5 \pm 2.50$ & $1.5 \pm 0.15$ \\
\hline Survival rate (\%) & $89.5 \pm 1.30$ & $87.8 \pm 1.42$ & $92.0 \pm 0.96$ & $84.6 \pm 1.90$ & $85.6 \pm 2.50$ & $90.5 \pm 2.32$ & $80.0 \pm 3.61$ & $88.1 \pm 1.76$ \\
\hline
\end{tabular}

Significant effects compared with first parity: ${ }^{*} P<0.05,{ }^{\star \star} P<0.01,{ }^{\star \star \star} P<0.001$ 
Table 3 Means $( \pm$ SE) reproductive performance by parity of Landrace sows in Lithuania

\begin{tabular}{|c|c|c|c|c|c|c|c|c|}
\hline & 1 & 2 & 3 & 4 & 5 & 6 & $>=7$ & Total \\
\hline No. of litters & 248 & 104 & 90 & 66 & 54 & 35 & 31 & 628 \\
\hline Total number of born & $11.0 \pm 0.11$ & $11.4 \pm 0.20$ & $11.9 \pm 0.20^{\star \star \star}$ & $11.2 \pm 0.22$ & $11.8 \pm 0.28^{* \star}$ & $10.9 \pm 0.37$ & $11.3 \pm 0.40$ & $11.3 \pm 0.08$ \\
\hline Born alive & $10.7 \pm 0.11$ & $11.2 \pm 0.20^{*}$ & $11.7 \pm 0.21^{\star \star \star}$ & $11.0 \pm 0.22$ & $11.6 \pm 0.29^{* *}$ & $10.7 \pm 0.37$ & $11.1 \pm 0.42$ & $11.0 \pm 0.08$ \\
\hline Stillborn & $0.3 \pm 0.04$ & $0.2 \pm 0.04^{\star}$ & $0.2 \pm 0.04$ & $0.2 \pm 0.06$ & $0.3 \pm 0.07$ & $0.3 \pm 0.09$ & $0.3 \pm 0.10$ & $0.3 \pm 0.02$ \\
\hline \multicolumn{9}{|l|}{ At 21 days old } \\
\hline No. of piglets & $10.5 \pm 0.12$ & $11.2 \pm 0.20^{\star *}$ & $11.6 \pm 0.21^{\star \star \star}$ & $10.8 \pm 0.23$ & $11.5 \pm 0,29^{* *}$ & $10.5 \pm 0.36$ & $10.8 \pm 0.44$ & $10.9 \pm 0.08$ \\
\hline Litter weight (kg) & $55.9 \pm 0.56$ & $60.1 \pm 0.95^{\star * *}$ & $61.4 \pm 0.88^{\star \star *}$ & $56.9 \pm 1.12$ & $60.1 \pm 1.26^{* *}$ & $55.2 \pm 1.70$ & $56.8 \pm 2.11$ & $57.8 \pm 0.38$ \\
\hline Individual weight (kg) & $5.3 \pm 0.05$ & $5.4 \pm 0.09$ & $5.3 \pm 0.08$ & $5.3 \pm 0.10$ & $5.3 \pm 0.11$ & $5.3 \pm 0.16$ & $5.2 \pm 0.19$ & $5.3 \pm 0.04$ \\
\hline \multicolumn{9}{|l|}{ At weaning } \\
\hline Weaning age (days) & $30.5 \pm 0.16$ & $29.5 \pm 0.27^{\star \star}$ & $30.1 \pm 0.31$ & $30.5 \pm 0.31$ & $30.1 \pm 0.46$ & $30.9 \pm 0.40$ & $30.7 \pm 0.40$ & $30.3 \pm 0.11$ \\
\hline Wean number & $10.5 \pm 0.12$ & $11.1 \pm 0.20^{\star *}$ & $11.6 \pm 0.21^{\star \star \star}$ & $10.8 \pm 0.23$ & $11.4 \pm 0.30^{\star *}$ & $10.5 \pm 0.36$ & $10.8 \pm 0.44$ & $10.9 \pm 0.08$ \\
\hline Litter weight (kg) & $111.3 \pm 1.12$ & $116.5 \pm 2.01^{*}$ & $120.6 \pm 2.15^{\star \star *}$ & $114.6 \pm 2.23$ & $119.9 \pm 2.83^{* *}$ & $112.9 \pm 3.85$ & $114.5 \pm 4.24$ & $114.9 \pm 0.79$ \\
\hline Individual weight (kg) & $10.6 \pm 0.11$ & $10.5 \pm 0.18$ & $10.4 \pm 0.19$ & $10.6 \pm 0.29$ & $10.5 \pm 0.25$ & $10.8 \pm 0.37$ & $10.6 \pm 0.39$ & $10.5 \pm 0.07$ \\
\hline Dead number & $0.1 \pm 0.03$ & $0.1 \pm 0.02$ & $0.1 \pm 0.03$ & $0.2 \pm 0.05$ & $0.1 \pm 0.06$ & $0.2 \pm 0.07$ & $0.2 \pm 0.08$ & $0.1 \pm 0.02$ \\
\hline Survival rate (\%) & $98.8 \pm 0.84$ & $99.5 \pm 0.23$ & $99.4 \pm 0.43$ & $98.0 \pm 1.26$ & $98.9 \pm 1.06$ & $98.1 \pm 1.21$ & $98.0 \pm 1.19$ & $98.9 \pm 0.96$ \\
\hline
\end{tabular}

Significant effects compared with first parity: ${ }^{\star} P<0.05$, ${ }^{\star \star} P<0.01,{ }^{\star * \star} P<0.001$ 


\section{Discussion}

The number of piglets born alive is a common reproductive trait that is recorded in many farms because it is highly correlated with the number of weaned piglets (Dekkers et al., 2011). The heritability coefficient is approximately $10-13 \%$ for litter size and $5-8 \%$ for the survival rate of piglets in the pre-weaning period (Hanenberg et al., 2001; Bidanel, 2011). Maternal behaviour has considerable influence on the latter indicator, since aggressive sows often overlie and crush their offspring during lactation. Such sows have to be culled to increase genetic potential for prolificacy with the aim of weaning as many healthy piglets as possible (Rydhmer, 2000; Marchant et al., 2001; Andersen et al., 2005). Škorjanc et al. (2007) and Beyga and Rekiel (2010) reported that prolificacy and the number of stillborn piglets were higher in multiparous sows than in primiparous sows. An analysis of the breeds revealed that sows in their second parity and later produced larger litters compared with primiparous sows. In most cases, the number of stillborn piglets per litter increased with litter size. In Large White and Landrace sows increased litter size was observed until parity 5, and in the open population of Lithuanian White sows until parity 6 . These differences were statistically significant compared with primiparous sows in all analysed breeds. An increase in sow prolificacy from parity 1 through parity 5 (Čechova \& Tvrdon, 2006) or 6 (Škorjanc et al., 2007) was also observed in studies conducted in the Czech Republic and Slovenia, respectively. In a study by Karpiesiuk et al. (2018), who analysed the longevity and reproductive performance of 190 crossbred Redone pigs, the average numbers of piglets born alive and stillborn per litter were 13 and 0.67 , respectively. A positive correlation was found between sow fertility and the size of subsequent litters $(r=0.17, P \leq 0.01)$, which indicates that sow fertility does not always decrease with age. The group of sows that remained in the herd for the longest period (group 5, at least 12 litters) were characterized by the highest fertility $(P \leq 0.01)$ and a similar number of stillborn piglets in comparison with the remaining groups.

In following the rules of Lithuanian breeding pig productivity control, evaluation, information collection, and provision (2003) the relative milk yield of sows was determined based on litter weight at 21 days old The milk yield of sows depends on the number of piglets and their individual weight at 21 days old, and is correlated directly with litter weight at birth. Milk yield is influenced considerably by environmental conditions and development of the mammary glands (Bidanel, 2011). In the current study, a significant increase in the number of piglets and litter weight at 21 days old was observed in Landrace sows in their fifth parity.

The number of weaned piglets and their development is an economically important indicator of the reproductive performance of sows (Hogberg \& Rydhmer, 2000). In the breeding centres, piglets were weaned at ages ranging from 22 days (Large White) to 32 days (improved Lithuanian White). In seeking to increase litters per sow per year, piglets should be weaned not earlier than 28 days old (Council Directive 2008/120/EC 2009). However, piglets can be successfully weaned at least seven days earlier at 21 days old, if they are housed under conditions where the premises are thoroughly cleaned before housing a new group, and are separated from the areas in which sows are kept to minimize the risk of transferring diseases. In the current study, the breeding centre for Large White sows complied with all these requirements, and the piglets were weaned at 22 days old on average. The survival rate of pre-weaning piglets ranged from $88.1 \%$ (Large White) to $98.9 \%$ (Landrace). Therefore, earlier weaning could have been related to the greater death loss. A good pre-weaning survival rate is $90 \%$ or more, and a poor survival rate is $80 \%$ or less (Kerr \& Cameron, 1995). In the current study, a decrease in the pre-weaning survival rate of piglets was observed in litters from sows in their seventh and later parities. Knecht et al. (2015) demonstrated that parity had a minor effect on the number of weaned piglets. In the present study, sows that produced their first litter had a smaller number of piglets and lower litter weight at weaning compared with Large White sows of parity 3, and Landrace sows of parities 2, 3, and 5 . In improved Lithuanian White sows, parity had no significant effect on the number and litter weight of weaned piglets.

\section{Conclusions}

Sows of these breeds can be used effectively in breeding herds until their fifth or sixth parity without compromising the reproductive rate, if adequate feeding and housing conditions are provided and the reasons for culling are eliminated. Piglet survival rate tended to be adversely affected for sows in their seventh parity and beyond.

\section{Authors' Contributions}

All authors participated in the entirety of this research and have read and approved the final manuscript. 


\section{Conflict of Interest Declaration}

The authors have no conflict of interest to declare.

\section{References}

Andersen, I.L., Berg, S. \& Boe, K.E., 2005. Crushing by the mother sow (Sus scrofa) - purely accidental or a poor mother? Appl. Anim. Behav. Sci. 93, 229-243.

Arango, J., Misztal, I., Tsuruta, S., Culbertson, M. \& Herring, W., 2005. Threshold-linear estimation of genetic parameters for farrowing mortality, litter size and test performance of Large White sows. J. Anim. Sci. 83, 499-506.

Beyga, K. \& Rekiel, A., 2010. The effect of the body condition of late pregnant sows on fat reserves at farrowing and weaning and on litter performance. Arch. Tierz. 53, 50-64.

Bidanel, J.P., 2011. Biology and genetics of reproduction. In: M.F. Rothschild \& A. Ruvinsky (eds). The genetics of the pig. 2nd edition. CAB, Wallingford, Oxfordshire, UK, pp. 218-241.

Čechova, M. \& Tvrdon, Z., 2006. Relationships between backfat thickness and parameters of reproduction in the Czech Large White sows (short communication). Arch. Tierz. 49, 363-369.

Dekkers, J.C.M., Mathur, P.K. \& Knol, E.F., 2011. Genetic improvement of the pig. In: M.F. Rothschild \& A. Ruvinsky (eds). The genetics of the pig. 2nd edition. CAB, Wallingford, Oxfordshire, UK, pp. 390-425.

Eissen, J.J., Apeldoorn, E.J., Kanis, E., Verstegan, M.W.A. \& de Greef, K.H., 2003. The importance of a high feed intake during lactation of primiparous sows nursing large litters. J. Anim. Sci. 81, 594-603.

Franczak, A., Zglejc, K., Waszkiewicz, E., Wojciechowicz, B., Martyniak, M., Sobotka, W., Okrasa, S. \& Kotwica, G., 2017. Periconceptional undernutrition affects in utero methyltransferase expression and steroid hormone concentrations in uterine flushings and blood plasma during the peri-implantation period in domestic pigs. Reprod. Fertil. Dev. 29, 14991508.

Guo, S.F., Gianola, D., Rekaya, R. \& Short, F.T., 2001. Bayesian analysis of lifetime performance and prolificacy in Landrace sows using a linear mixed model with sensoring. Livest. Prod. Sci. 72, 243-252.

Hanenberg, E., Knol, E.F. \& Merks, J., 2001. Estimates of genetics parameters for reproduction traits at different parities in Dutch Landrace pigs. Livest. Prod. Sci. 69, 179-186.

Hogberg, A. \& Rydhmer, L., 2000. A genetic study of piglet growth and survival. Acta Agr. Scand. 50, 300-303.

Hoving, L.L., Soede, N.M., Graat, E.A.M., Feitsma, H. \& Kemp B., 2011. Reproductive performance of second parity sows: Relations with subsequent reproduction. Livest. Sci. 140, 124-130.

Karpiesiuk, K., Jarczyk, A., Winiarski, Z., Milewska, W., Bugnacka, D., Kozera, W., Woźniakowska, A. \& Kleśniak, P., 2018. Sow longevity as an indicator of resistance to environmental stressors. Pol. J. Anim. Sci. 33, 17-28.

Kerr, J.C. \& Cameron, N.D., 1995. Reproductive performance of pigs selected for components of efficient lean growth. J. Anim. Sci. 60, 281-290.

Klimas, R. \& Klimienè, A., 2014. A culling analysis of sows in breeding centers in Lithuania. Vetinfo. 5, 14-17.

Klimienè, A. \& Klimas, R., 2011. Efficiency of improvement of Lithuanian White pigs breed by using English Large Whites. Vet. Med. Zoot. 54, 35-39.

Knecht, D., Srodon, S. \& Duzinski, K., 2015. The impact of season, parity and breed on selected reproductive performance parameters of sows. Arch. Anim. Breed. 58, 49-56.

Marchant, J.N., Broom, D.M. \& Corning, S., 2001. The influence of sow behavior on piglet mortality due to crushing. J. Anim. Sci. 72, 19-28.

Nagyne Kiszlinger, H., Farkas, J., Kover, G. \& Nagy, I., 2013. Selection for reproduction traits in Hungarian pig breeding in a two-way cross. Anim. Sci. Pap. Rep. 31, 315-322.

Rydhmer, L., 2000. Genetics of sow reproduction, including puberty, oestrus, pregnancy, farrowing and lactation. Livest. Prod. Sci. 66, 1-12.

Serenius, T. \& Stalder, K.J., 2004. Genetics of length of productive life and lifetime prolificacy in the Finish Landrace and Large White pig populations. J. Anim. Sci. 82, 3111-3117.

Sevon-Aimonen, M.L. \& Uimari, P., 2013. Heritability of sow longevity and lifetime prolificacy in Finnish Yorkshire and Landrace pigs. Agr. Food Sci. 22, 325-330.

Škorjanc, D., Brus, M. \& Čandek Potokar M., 2007. Effect of birth weight and sex on pre-weaning growth rate of piglets. Arch. Tierz. 50, 476-486.

Takai, Y. \& Koketsu, Y., 2008. Number of services and the reservice intervals in relation to suboptimal reproductive performance in female pigs on commercial farms. Livest. Sci. 114, 42-47.

Thaker, M.Y.C. \& Bilkei, G., 2005. Lactation weight loss influences subsequent reproductive performance of sows. Anim. Reprod. Sci. 88, 309-318.

Tucker, L.A., 2003. Simplistic statistics. A basic guide to the statistical analysis of biological data. Chalcomble, Welton Lincoln, UK. Pp. 65.

Zhao, Y., Liua, X., Moa, D., Chenb, Q. \& Chena, Y., 2015. Analysis of reasons for sow culling and seasonal effects on reproductive disorders in Southern China. Anim. Reprod. Sci. 159, 191-19. 